\title{
Emotional security and interparental conflict: responses of adolescents from different living arrangements
}

\author{
Silvia López-Larrosa ${ }^{1}$ Vanesa Sánchez-Souto ${ }^{1}$ Anh P. Ha ${ }^{2}$ E. Mark Cummings ${ }^{2}$ \\ ${ }^{1}$ Departamento de Psicología Facultad de Ciencias de la Educación, Universidade da Coruña, A Coruña, \\ Spain \\ ${ }^{2}$ University of Notre Dame, Notre Dame, USA
}

\begin{abstract}
Objectives. Interparental conflict (IPC) is linked with adolescents' heightened emotional insecurity about family relations. Our aim was to examine Spanish adolescents' differential responses to IPC as a function of specific dimensions of IPC and emotional security, in two different living arrangements.

Methods. Participants were 162 adolescents $(M$ age $=15.55$ years $)$, comprising a community sample of 86 adolescents living with their families (CF) and an at-risk sample of 76 adolescents living in residential care (RC). Six video-recorded vignettes depicting everyday IPC were presented, two each of escalated (destructive), constructive, and unresolved conflicts. Multiple dimensions of adolescents' emotional security responses (i.e., emotional reactivity, behavioral regulation, and cognitive representations) were examined. Results. Constructive conflicts generated more intense and positive emotions, more constructive cognitive representations, and a behavioral regulation pattern of higher interference. As expected, destructive conflicts generated negative emotions, destructive cognitive representations, and less interference in both groups. Unresolved conflicts had effects on adolescents that were closer to those of destructive conflict. RC adolescents were more emotionally insecure and reactive in response to constructive conflicts than $\mathrm{CF}$ adolescents and exhibited a blunted pattern of response to destructive conflicts, even when overall levels of emotional security were controlled. Sensitization to constructive conflict also appeared in adolescents low in emotional security. Girls evidenced greater involvement, less positivity and more negativity than boys.

Conclusions. Our results have implications for understanding RC adolescents' greater risk for adjustment problems and for broadening the scope of Emotional Security Theory in future research to include additional living arrangements.
\end{abstract}

\section{Keywords}

Interparental conflict; Adolescent; Residential care; Emotional security 
Interparental conflict (IPC) is a potential threat to adolescents' emotional security in the family. According to Emotional Security Theory (EST), adolescents need to feel safe in their families (Cummings and Davies 2010). Maintaining a sense of security is a chief goal among children and adolescents and has repeatedly been linked to the well-being and adjustment of adolescents (Cummings and Davies 2010; Cummings et al. 2015; Davies et al. 2016). Responses to IPC have been shown to be a function of family contexts; specifically, greater exposure to conflict in the past, which decreases adolescents' emotional security, has been linked with sensitization and higher levels of reactivity to current conflicts (Cummings and Davies 2002). Thus, adolescents with differing levels of emotional security would be expected to react differently when confronted to IPC (Cummings and Davies 2010). Accordingly, adolescents in residential care (RC), who have been removed from their home environments due to a variety of factors that threaten the stability of the home environment, including IPC, would be expected to be more emotionally insecure and reactive to the same conflict scenarios compared to adolescents from community settings. Spanish data indicate that a high percentage of institutionalized adolescents have negative representations of their families (Campos 2013) and come from families in which parents show inadequate parental roles, maltreat them, or involve them in family violence (Criado del Rio et al. 1990; Luzón García and Dominguez Alonso 2014; Martín and Dávila 2008). Thus, it might be expected that adolescents in RC exhibit distinctive patterns of responding compare to adolescents living with their families. However, questions remain about how multiple living arrangements affect children' responsivity to conflict. Certain living arrangements, particularly adolescents in RC, are underrepresented. Given that emotional insecurity, most prominently indexed by heightened emotional reactivity, is linked with adolescents' adjustment problems, indexing these relations in a controlled context would have implications for understanding the greater risk for adjustment problems among adolescents in RC.

Adolescents' responses to conflict are also a function of the expression of conflict, as IPC is multidimensional (Cummings and Davies 1994). Previous studies with adolescents who live with their families have shown that adolescents differentiate between conflicts in which their parents resolve their differences, show positive affection and discuss calmly, and conflicts in which parents escalate the disagreement, do not reach agreements, and are physically or verbally aggressive or hostile (Koss et al. 2011; McCoy et al. 2009). The first type of conflict has been characterized as constructive conflict, while the second is considered destructive conflict (Cummings and Davies 2010). Furthermore, an additional type of conflict behavior is identified in which the disagreement is not escalated because one of the parents exits the situation, which leaves the disagreement unresolved. This type of unresolved conflict could be roughly defined as destructive, although it has been previously differentiated from escalating conflicts. Research has shown that adolescents are sensitive to different dimensions of conflict and conflict resolution, distinguishing saliently among constructive, unresolved, and escalated conflicts (Koss et al. 2011; Shifflett- Simpson and Cummings 1996).

Adolescents' responding to conflict may take multiple forms of expression. According to EST (Cummings and Davies 2010), children's and adolescents' emotional security in the family manifests through regulatory processes that include emotional reactivity, behavioral regulation, and internal representations (Cummings and Miller-Graff 2015; Koss et al. 2011). Emotional security encompasses children and adolescents' efforts to manage emotions, behaviors, and cognitions in response to conflict, which form patterns of responding that develop over time (Thompson et al. 2008). In this study, we will examine adolescents' immediate responses to IPC, considering 1) emotional reactivity, 2) behavioral regulatory responses, and 3) cognitive responses. Emotional reactivity to destructive conflict (i.e., escalated conflict) comprises emotions such as anger, sadness, fear, or guilt (Cummings and Davies 1999, 2002; Goeke-Morey et al. 2003). Unresolved conflict, without escalation, tends to produce sadness and uneasiness (ShiffletSimpson and Cummings 1996). When parents use constructive conflict tactics, children manifest more positive emotions, such as happiness (Cummings et al. 2002; Goeke-Morey et al. 2007). 
Following EST, when confronted with IPC, adolescents may exhibit different behavioral reactions. Some studies suggest that adolescents get involved in IPC as their confidence in their parents' ability to reach a solution decreases (Davies et al. 1999; Goeke-Morey et al. 2003), while others report that adolescents avoid destructive conflicts as their parent's behaviors are threatening for them (Buehler et al. 2007; Davies and Martin 2014; Davies and Sturge- Apple 2007; Harold et al. 2004; Rhoades 2008). Nonetheless, research has identified young adolescents as highly involved in their parents' conflicts. Moreover, involvement combined with high emotional reactivity negatively affects young adolescents' psychological maladjustment (Davies et al. 2015). According to a revised version of EST, EST-R (Davies and Martin 2014), a social defense system (SDS) associated with emotional insecurity also contributes to the organization of children's behaviors. This system allows adolescents to identify and defend from hostile others in the social group, parents included. Intervening in conflict is held to be one of the most effective coping strategies for children in the face of IPC (Schermerhorn et al. 2007), especially when conflicts are threatening (Grych and Fincham 1993). At this time, given the discrepancy in the literature regarding adolescents' behavioral responses to IPC, we are especially interested in examining empirically how adolescents respond behaviorally to conflicts in a controlled situation. When the same conflicts are presented experimentally to adolescents from different living arrangements and different levels of emotional security, disparities in reactivity may be attributed to their disparate histories and levels of emotional security.

In terms of cognitions, according to EST, adolescents develop representations based on their experiences about the meaning that IPC has for them and their families (Davies et al. 2002). Adolescents who are emotionally insecure hold less positive and more hostile representations of the consequences IPC may pose to them or to their families. Given that the degree in which a conflict is solved alters the cognitive representation of IPC (Ha et al. 2018), in this study, we will analyze adolescents' interpretations of the constructiveness or destructiveness of IPC as measured by the degree of resolution of simulated IPC. We assume that there will be differences in adolescents' evaluation of conflict constructiveness or destructiveness, as indexed by degree of resolution, depending on their emotional security and their living arrangements.

Research has suggested that adolescents are more sensitive to the emotional valence of a conflict's ending than younger children are (Davies et al. 1996; Goeke-Morey et al. 2013); however, findings are not always consistent (Richmond and Stocker 2007). Nonetheless, it could be expected that adolescents will respond more discriminately to resolved versus unresolved conflicts. In addition, as adolescents' cognitive sophistication increases, they are more capable of reporting on their internal and behavioral states. However, to our knowledge, most research grounded in EST has been undertaken with adolescents living with both parents or living with, at least, one parent or family figure.

It is difficult to study real conflicts directly in a naturalistic or laboratory setting, especially when the research questions of interest revolve around adolescents' reactions to their parents' conflicts; yet, it can be argued that reactions to conflicts are of notable importance to consider when examining how IPC affects the family beyond the interparental subsystem. Besides, the study of immediate responses to IPC between the parents in the home raises ethical considerations, especially for destructive conflict. Analog contexts provide a particularly rigorous, experimental way to isolate adolescents' reactions to IPC that may be related to risk for adjustment problems (Cummings 1995). Thus, researchers have advanced experimental, including analog, methodologies that can be more easily controlled in terms of duration, content, and mode of delivery of conflict scenarios without interfering in the actual functioning of the family, including the interparental relationship. Videotapes depicting simulated conflicts between a couple can accurately depict verbal and non-verbal components of conflict and have increasingly been preferred to audiotaped simulated conflicts used in previous studies (Cummings et al. 1989; Cummings et al. 1991). Studies have evolved from those using more than 10 videotaped vignettes (Shelton et al. 2006; Shifflett- Simpson and Cummings 1996) to those that present about six or seven vignettes lasting 1 min for setting the conflict and a few seconds for the conclusion (Koss et 
al. 2011; Shamir et al. 2005). As for the content, including constructive, unresolved and destructive vignettes is necessary to capture and study the differential impact of the diverse conflict tactics on adolescents' emotional security (Cummings et al. 2003; Goeke-Morey et al. 2003).

Analog methodologies (videotaped simulated conflicts) were used in this study. We recruited adolescents living in Spain with their families and in residential care, both groups comprising of participants with low and high emotional security, to address two interrelated questions. Our goal was to identify whether, controlling for levels of emotional security, adolescents living in residential care would display higher sensitization to IPC than adolescents living with their families, and to examine the relation between emotional security and IPC regardless of living arrangements. Therefore, living arrangement (family and residential care) and level of emotional security (low and high) were considered variables of interest in assigning participants to groups and, relatedly, analyzing the participants' responses to simulated IPC. A first aim was to examine the emotional reactivity (intensity and type of emotion), behavioral regulation, and internal representations of conflict resolution of adolescents, independent of living arrangement and levels of emotional security, after watching simulated interparental destructive (escalating), unresolved, and constructive conflicts. The hypothesis was that constructive conflict would elicit the least emotional reactivity and destructive conflict the most emotional reactivity. Relatedly, a second aim was to compare the emotional security and the emotional, behavioral and cognitive responses of adolescents from different living arrangements. Consistent with differences in family histories of conflict, community adolescents were expected to evidence the least reactivity and adolescents in residential care the greatest reactivity to all forms of conflict, even when controlling for levels of emotional security. A third aim was to analyze adolescents' responses as a function of their emotional security about family relationships (low or high). Our hypothesis was that more emotional insecure adolescents, regardless of living arrangement, will show greatest reactivity to all forms of conflict compared to more secure adolescents. Finally, we will examine the effects of both living arrangement and emotional security on adolescents' responses when controlling for gender and type of family. It has proven difficult to draw any clear-cut conclusions regarding the role of adolescent gender in the study of the impact of family conflict (Cummings and Davies 2010; Rhoades 2008), with even large-sample studies failing to find consistent patterns of results. However, the living arrangements sampled (e.g., RC adolescents) and cultural context (i.e., Spain) assessed in this study have not been examined in the past. Thus, although these analyses should be regarded as exploratory given limited past study in the contexts addressed in this study, the possibility exists that gender differences may emerge.

\section{Method}

\section{Participants}

To gain access to the participants, local authorities in the Child Protection Services of the region were contacted. Once the study was approved by the local authorities, we reached out to the principals of the residential care centers for permission for data collection. In the centers where data collection was permitted, adolescents were informed of the study, and those who assented participated. Adolescents currently living with their families were approached through the schools they were attending. Principals were contacted, and teachers were consulted. Once the school approved the study, parents were sent informed consent letters. Those adolescents living with their families whose parents consented participated in this study after their own assents were given. The recommended sample size to detect small effects in this mixed design is 208, given our expected means and variabilities. Recruitment yielded 162 adolescents from the Northwest region of Spain whose ages ranged between 12 and 19 years old $(M$ age $=15.55, S D=1.75)$. Ninety-one were in residential care and seventy-one were living with their families (see Table 1 for demographics). The families they came from were two parent, single parent, and other family forms. In 34 cases, 
the single parent was the mother while in 10 cases the single parent was the father. In one case, the participant did not provide information about his/her family composition. Adolescents in other family forms were not living with their fathers and mothers. Instead, they were living with their adult siblings, their grandparents or other family members.

Table 1. Sociodemographics of the participant sample

\begin{tabular}{|c|c|c|c|c|}
\hline & & $\begin{array}{l}\text { Residential care } \\
n=91\end{array}$ & $\begin{array}{l}\text { Family } \\
n=71\end{array}$ & $\begin{array}{l}\text { Total } \\
n=162\end{array}$ \\
\hline \multirow[t]{2}{*}{ Emotional security in the family } & Low & 55 & 31 & 86 \\
\hline & High & 36 & 40 & 76 \\
\hline \multirow[t]{2}{*}{ Gender } & Male & 54 & 36 & 90 \\
\hline & Female & 37 & 35 & 72 \\
\hline \multirow[t]{3}{*}{ Family type } & Two parents & 29 & 58 & 87 \\
\hline & Single parent & 34 & 10 & 44 \\
\hline & Other & 27 & 3 & 30 \\
\hline
\end{tabular}

Participants were selected considering two criteria: their level of emotional security and whether they were living with their family in the community (CF) or in residential care (RC). Participants who lived with their families were recruited from five high schools, and those in RC were recruited from 16 centers. Out of confidentiality concerns, we did not have access to RC records, and we cannot compile data regarding the specific reasons the adolescents were under the custody of Child Protection Services. Residential care is intended to protect minors at risk of maltreatment or neglect from their family members, in cases where parents were not available to provide adequate care for the children, and other precarious circumstances for the children's welfare.

In this study, gender was balanced across the groups. Participants of both sub-samples were extracted from a sample of 907 adolescents living with their families and in residential care who completed the Spanish version of the Security in the Family System Scale (SIFS; Forman and Davies 2005; López Larrosa et al. 2016) (see Measures). In order to isolate more clearly the effect of emotional security in adolescents' responses to analog IPC, we predetermined two levels of emotional security of interest, low and high. Then, from that sample of 907 adolescents, we extracted the security scores for percentiles 75 and 25 in the security subscale of SIFS. According to these values, participants in the upper 75th percentile (security score $>29$ ) in SIFS's security subscale (explained in Measures) were included in the high emotional security group of CF and RC subsamples. Participants in the 25 th percentile or lower (security score $<24$ ) on SIFS's security subscale were included in the low emotional security group of CF and RC subsamples. By doing so, we hoped to isolate the effect of emotional security regardless of the adolescent's living allocation. Significant differences were found when considering type of family and emotional security, $\chi^{2}(161)=13.15, p=0.001$. More adolescents from single families were in the low emotional security subsample while more adolescents from two parent families were in the high emotional security subsample. Differences were also found when considering type of family and living arrangement, $\chi^{2}(161)=13.15, p=0.001$. Among RC adolescents, single families and other family forms predominated while two parent families were more common among CF adolescents. 


\section{Procedure}

All participants completed the SIFS, viewed six video recorded conflict vignettes and answered the MOV. These instruments and materials are described below in Measures. Adolescents first completed the SIFS in groups either at school or at their residential care center. In all cases, the same researcher (one of the authors) was present to supervise the data collection process.

Because of the restricted access to residential care centers, all data in those centers had to be collected at once. Participants in RC viewed the video-recorded conflict vignettes and answered to the MOV the same day they completed the SIFS. Those included in this study were those with emotional security scores in the highest and lowest $25^{\text {th }}$ percentile of this RC subsample. Participants living with their parents (community family; $\mathrm{CF}$ ) viewed the videos and answered the MOV if they were selected on the basis of their score on emotional security (i.e., highest and lowest 25 th percentile). For these CF participants, videos were shown on a different day from the initial visit.

Participants in both subsamples viewed the vignettes alone in a facility room provided by a school or a residential care center. Six vignettes were chosen for each participant at random. Two vignettes had a destructive end, two had an unresolved end, and two had a constructive end. All vignettes' ends were counterbalanced, but the experimental condition imposed that the last one was constructive to align with ethical considerations and to minimize harms or risks to the participants. We expect the harms and risks to the participants to be minimal, as we took care to minimize actual violence shown in the vignettes and selected the topics to be mundane in nature. After watching each vignette, participants completed the MOV.

\section{Measures}

\section{Security in the Family System scale (SIFS)}

The SIFS was developed by Forman and Davies (2005). It was translated to Spanish and backtranslated by two skilled psychologists and two native English teachers, attending to meaning and cultural relevance following Muñiz et al. (2013) suggestions for translation and cultural adaptation of psychological instruments. In addition, two studies with 510 and 845 adolescents were conducted to further identify the scale properties of the SIFS in its Spanish translation (López Larrosa et al. 2012, 2016). The SIFS assesses children's and adolescents' perceived security in the family system. It comprises 22 items organized in three dimensions: Preoccupation, Security, and Disengagement. The subscale reflecting insecure patterns of "Preoccupation" measures children's concern and anxiety about their families. The subscale reflecting insecure patterns of "Disengagement" assesses children's tendency to emotionally disconnect from their families and "downplay the significance of the family in their lives" (Forman and Davies 2005, p. 902). The subscale "Security" measures how safe and confident children feel in their families. The SIFS was completed by the initial sample of 907 adolescents from which the participants in this study were extracted. Factor analyses confirmed the three factors identified by Forman and Davies (2005). In this study, the internal consistency coefficients of the subscales were adequate to good, $\alpha=.84$ for Security and Preoccupation, and $\alpha=.79$ for Disengagement. 


\section{"My opinion about the video" (MOV) Questionnaire}

This questionnaire (originally "Mi opinión sobre el vídeo") was developed ad hoc. MOV is meant to measure responses to analog videos depicting IPC, and its main goal is to provide ecological validity. MOV explores the responses that the participant adolescents give to each conflict situation they watch (see Conflict vignettes next) considering their emotional reactivity (the intensity and the type of emotion generated), their behavioral regulation (what they would do in a similar situation), and their internal cognitive representations of the constructiveness of the situation (how resolved the conflict was) based on previous studies (El-Sheikh et al. 1994; Koss et al. 2011) and informed by Davies et al.'s SIS (Security in the Interparental Subsystem scale, child report; Davies et al. 2002). Thus, adolescents saw two vignettes with destructive endings, two with unresolved endings and two with constructive endings. Emotional reactivity, cognitive representations and behavioral regulation were calculated for each pair of constructive, destructive and unresolved conflicts.

To evaluate emotional reactivity, the MOV questionnaire prompted participants to identify the emotions that they had after watching each video, differentiating between positive emotions (happy and feeling well) and negative emotions (angry, scared, and sad). Then, participants were asked to rank the intensity of the emotion experimented, either positive or negative, using a Likert scale with anchors 0 (Nothing) to 10 (Very High). This way, there was a positive emotional reactivity and negative emotional reactivity for each vignette for each participant. Positive emotional reactivity for each pair of constructive, destructive and unresolved conflicts was calculated by summing the two scores. The negative emotional reactivity for each pair of constructive, destructive and unresolved conflicts were also determined by summing the two scores. Values range from 0 to 20 for both positive and negative emotional reactivity.

For cognitive representations (conflict resolution), participants are asked "is the problem solved?" A Likert scale is provided with anchors 0 (Nothing) to 10 (Very High) to rate the degree of resolution of the conflict situation from not solved to very highly solved. In this study, we will refer to constructiveness when the degree of resolution is high and to destructiveness when the degree of resolution is low. The measures of each pair of constructive, unresolved and destructive conflicts are summed up. Values range from 0 to 20.

Following the MOV protocol, the adolescent is also asked "What would you do if you were in the same room with them?" to identify behavioral regulation. Two distinct behavioral strategies are identified: leave the room and interfere/get involved in the conflict. Values range from 0 (Leave) to 10 (Get Involved), and adolescents were instructed to rate where their likely behavior would fall from the continuum of leaving the room to getting involved in the conflict, with scores near 0 reflecting relative likelihood of choosing to leave and scores near 10 indicating relatively greater likelihood of getting involved. The measures of each pair of constructive, unresolved and destructive conflicts are summed up. Values range from 0 to 20. Thus, the closer the value is to 20 , the more likely the adolescents would interfere and the closer to 0 , the more likely they would leave the room.

\section{Conflict Vignettes}

A DVD called "Conflicto en ocho historias" (literally "Conflict in eight stories") was developed (Sánchez-Souto and López-Larrosa 2010). This DVD was specifically developed for this research based on Cummings' and Davies' previous work (Cummings et al. 1989; Koss et al. 2011). Eleven written vignettes about everyday family conflicts were initially created. Three experts (two University professors and one practicing psychologist) evaluated the vignettes, considering the authenticity of the conflict and the constructiveness or destructiveness of the situation using a Likert scale ( $0=$ "Nothing" to $3=$ "A lot"). The three possible endings were also evaluated using the same scale. Eight vignettes were selected from these evaluations considering 
the agreement in the experts' evaluation about how realistic they were and their degree of hostility, affection, and solution. The topics of conflict on the DVD included family conflicts about finances, leaving school, curfew, children school problems, watching a particular television program, getting home late, washing the dishes, and in laws (see https://youtu.be/9M3v3qAPvwk), which are, respectively, Vignettes 1 to 8 . To develop the visual vignettes, either professional actors or amateurs were recruited and voluntarily participated without compensation. In the interest of authenticity, each vignette was recorded in a different location, usually the homes of the actors or those of their friends. Kitchens and living-rooms were the most common locations. Each vignette in the DVD lasts $1 \mathrm{~min}$ and $15 \mathrm{sec}$. The first minute of each video presented a conflict situation, with the conflict ending presented in the last $15 \mathrm{sec}$. In all the vignettes, two adults (man and woman), who were different in each story, depicted the mother and the father. The stories were constructed to be different in content to avoid participant satiation when watching the videos; moreover, because the topics varied across videos, the aggregated results should be more generalizable.

There were three possible endings for each of the eight vignettes. The destructive ending featured intense negative emotions, raised voices, and escalated conflict. The constructive ending showed the adults reaching an agreement and expressing affection and positive emotions. The unresolved ending featured one partner leaving the room, the conflict was unfinished. All destructive endings, across vignettes, share the same core features, and this principle also applies to constructive and unresolved endings across vignettes. Only one version of each vignette, i.e., whether the ending was destructive, constructive, or unresolved, was shown to each participant.

In order to determine if the three conflict endings (destructive, unresolved, and constructive) of the eight vignettes were equivalent in relation to the dimensions measured in the MOV (emotional reactivity, cognitive representation of conflict resolution and behavioral regulation), ANOVAs were performed on the participants in this study. Analyses showed no significant differences in conflict responses for destructive and unresolved conflict endings. For constructive conflict endings, no significant differences were found for emotional reactivity, but there were significant differences between the two versions of constructive conflict endings in cognitive representations and behavioral regulation, $F(7,309)=4.26, p<.001$ and $F(7,311)=2.92, p<.001$ respectively. Post-hoc Sheffé tests showed that the constructive endings of vignettes 7 and 8 were deemed to be different in degree of resolution (cognitive representation). Vignette 7 , which showed a couple arguing about who has to wash the dishes, has the lower degree of resolution. Vignette 8, which shows a couple arguing about their in-laws, has the higher degree of resolution. In the current study, the constructive end of vignette 7 was viewed by 45 participants, composed of 18 girls and 27 boys with low $(n=27)$ and high security $(n=18)$ and either living with their families $(n=19)$ or in RC $(n=26)$. The constructive end of vignette 8 was viewed by 35 participants, 15 girls and 20 boys with low $(n=18)$ and high security $(n=17)$ and either living with their families $(n=16)$ or in RC $(n=19)$. Post-hoc Sheffé identified differences between Vignettes 5 and 6 in behavioral regulation. Vignette 5, which shows a couple who argues about watching a television program, had the greater degree of interference by children while Vignette 6 , which shows a couple arguing because the husband arrived home late, had the lower degree of interference. The Constructive end of Vignette 5 was viewed by 54 participants, 25 boys and 29 girls with low $(n=23)$ and high emotional security $(n=31)$ and either living with their families $(n=23)$ or in $\mathrm{RC}(n=31)$ Constructive end of Vignette 6 was viewed by 42 participants, 21 girls and 21 boys, with low $(n=22)$ and high emotional security $(n=20)$ and either living with their families $(n=20)$ or in RC $(n=22)$. The vignettes were watched by a balanced number of participants (e.g., by gender, emotional security and living arrangement). 


\section{Data Analyses}

Data were analyzed using SPSS 23.0 (IBM Corp., Armonk, NY, USA). GLIMMPSE was used for power calculation (Kreidler et al. 2013) using covariance and correlation.

Descriptive statistics and correlations were calculated for socio-demographic descriptions and for power analyses. Chi-squares were calculated to compare the subsamples considering gender and type of family. $t$-tests were calculated to compare emotional security and emotional regulation, cognitive representations of conflict resolution and behavioral regulation of high and low emotional secure adolescents and F and RC adolescents in each conflict type. $2 \times 2 \times 3$ ANCOVAs were run differentiating between two levels of emotional security (low and high), two levels of arrangement allocation (living with their families, $\mathrm{CF}$, and in Residential care, RC) and three levels of conflict endings with covariates gender and type of family (two parents, single parent and other family forms). Listwise deletion was used for missing values.

\section{Results}

Tables 2 and 3 show descriptive statistics and correlations calculated for power analyses. The result of ad-hoc power analysis for an interaction of between- and within-group effects (RC-CF adolescents and type of conflict) was 0.66. Power analysis for all pairwise comparison withingroup, or between different conflict types without regard to living arrangement, was 1.0, as calculated on GLIMMPSE using cell means, standard deviations, and correlations among variables. Considering our first aim and hypothesis, results from t-tests showed that constructive conflicts generated higher positive emotional reactivity while destructive conflicts generated higher negative emotional reactivity. Destructive conflict generated the most emotional reactivity, but only for negative emotions. Destructive and unresolved conflicts did not differ in the intensity of the positive emotional responses. Pairwise comparisons revealed that constructive-destructive and unresolved-constructive conflicts significantly differed in both the positive and the negative emotions (see Table 4). Effect sizes were computed by adjusting the calculation of the pooled standard deviation with weights for the sample sizes. Effect sizes (Cohen's $d$ ) of the significant differences were large for comparisons of constructive conflict and either destructive or unresolved conflicts, respectively (Cohen 1988).

Table 2. Means and standard deviations for emotional reactivity (intensity of the positive, + , and negative, - , emotions), behavioral regulation and cognitive representations of destructive, unresolved and constructive conflicts of adolescents in residential care and living with their families

\begin{tabular}{llllll}
\hline Living arrangement & Conflict & $\begin{array}{l}\text { Emotional reactivity } \\
\text { positive } \\
\text { Mean (SD) }\end{array}$ & $\begin{array}{l}\text { Emotional reactivity } \\
\text { negative } \\
\text { Mean (SD) }\end{array}$ & $\begin{array}{l}\text { Behavioral } \\
\text { regulation } \\
\text { Mean (SD) }\end{array}$ & $\begin{array}{l}\text { Cognitive } \\
\text { representation } \\
\text { Mean (SD) }\end{array}$ \\
\hline \multirow{2}{*}{ Residential care } & Destructive & $0.71(2.56)$ & $12.41(4.50)$ & $10.40(7.08)$ & $2.85(4.15)$ \\
& Unresolved & $1.42(3.30)$ & $10.71(5.40)$ & $12.09(5.28)$ & $3.92(3.85)$ \\
Family & Constructive & $11.15(6.15)$ & $3.34(4.63)$ & $12.58(5.54)$ & $15.59(4.47)$ \\
& Destructive & $0.45(2.51)$ & $11.62(4.50)$ & $10.66(6.51)$ & $1.91(2.51)$ \\
& Unresolved & $0.73(2.84)$ & $11.10(4.46)$ & $11.52(5.57)$ & $3.56(3.95)$ \\
& Constructive & $11.97(5.83)$ & $2.05(3.39)$ & $12.10(3.77)$ & $16.89(3.12)$ \\
\hline
\end{tabular}


Table 3. Correlations between adolescents' emotional reactivity, cognitive representations and behavioral regulation to destructive, unresolved and constructive conflicts

\begin{tabular}{|c|c|c|c|c|c|c|c|c|c|c|c|c|c|}
\hline & & \multicolumn{4}{|c|}{ Destructive conflict } & \multicolumn{4}{|c|}{ Unresolved conflict } & \multicolumn{4}{|c|}{ Constructive conflict } \\
\hline & & ER+ & ER- & $\mathrm{CR}$ & $\mathrm{BR}$ & ER+ & ER- & $\mathrm{CR}$ & $\mathrm{BR}$ & ER+ & ER- & $\mathrm{CR}$ & $\mathrm{BR}$ \\
\hline \multirow[t]{4}{*}{ Destructive conflict } & $\mathrm{ER}+$ & - & & & & & & & & & & & \\
\hline & $\mathrm{ER}-$ & $-.40^{* *}$ & - & & & & & & & & & & \\
\hline & $\mathrm{CR}$ & $.18^{*}$ & -.02 & - & & & & & & & & & \\
\hline & $\mathrm{BR}$ & -.02 & -.02 & .01 & - & & & & & & & & \\
\hline \multirow[t]{4}{*}{ Unresolved conflict } & ER+ & $.58^{* *}$ & $-.23^{* *}$ & $.18^{*}$ & -.02 & - & & & & & & & \\
\hline & $\mathrm{ER}-$ & $-.33^{* *}$ & $.53^{* *}$ & .00 & -.09 & $-.49^{* *}$ & - & & & & & & \\
\hline & $\mathrm{CR}$ & .08 & -.04 & $.49^{* * *}$ & .04 & .04 & -.04 & - & & & & & \\
\hline & $\mathrm{BR}$ & -.06 & .03 & -.08 & $.31^{* *}$ & $-.19^{*}$ & $.20^{*}$ & -.04 & - & & & & \\
\hline \multirow[t]{4}{*}{ Constructive conflict } & ER- & .01 & .02 & -.04 & $-.18^{*}$ & .10 & .14 & .12 & -.14 & - & & & \\
\hline & ER- & .03 & $.20^{*}$ & .05 & .08 & -.01 & .08 & -.12 & $.16^{*}$ & $-.73^{* *}$ & - & & \\
\hline & $\mathrm{CR}$ & -.10 & .04 & .03 & .02 & .06 & .11 & $.17^{*}$ & -.09 & $.49^{* *}$ & $-.39^{* *}$ & - & \\
\hline & $\mathrm{BR}$ & $-.23^{* *}$ & $.16^{*}$ & -.13 & .15 & $-.23^{* *}$ & .14 & -.13 & $.17^{*}$ & -.10 & .14 & -.06 & - \\
\hline
\end{tabular}

$E R+$ positive emotional reactivity, $E R-$ negative emotional reactivity, $C R$ cognitive representations, $B R$ behavioral regulation

$* p<.05$ and $* * p<.01$ 
Table 4. Means, standard deviations, $t$-tests and effect sizes for emotional reactivity (intensity of the positive, + , and negative, -, emotions), cognitive representations and behavioral regulation of destructive, unresolved and constructive conflicts

\begin{tabular}{|c|c|c|c|c|c|c|}
\hline & Conflict & $n$ & $M(\mathrm{SD})$ & & $t$-test & Cohen's $d$ \\
\hline \multirow[t]{3}{*}{ Emotion reactivity +} & Destructive & 159 & $.61(2.55)$ & $\begin{array}{l}\text { Destructive } \\
\text { Unresolved }\end{array}$ & $t(158)=-2.45^{*}$ & 0.18 \\
\hline & Unresolved & 155 & $1.15(3.15)$ & $\begin{array}{l}\text { Destructive } \\
\text { Constructive }\end{array}$ & $t(156)=-20.96^{* *}$ & 2.36 \\
\hline & Constructive & 157 & $\begin{array}{l}11.50 \\
(6.01)\end{array}$ & $\begin{array}{l}\text { Unresolved } \\
\text { Constructive }\end{array}$ & $t(154)=-19.70 * *$ & 2.15 \\
\hline \multirow[t]{3}{*}{ Emotion reactivity - } & Destructive & 155 & $\begin{array}{l}12.10 \\
(4.53)\end{array}$ & $\begin{array}{l}\text { Destructive } \\
\text { Unresolved }\end{array}$ & $t(154)=3.27 * *$ & 0.25 \\
\hline & Unresolved & 155 & $\begin{array}{l}10.88 \\
(5.01)\end{array}$ & $\begin{array}{l}\text { Destructive } \\
\text { Constructive }\end{array}$ & $t(156)=21.01 * *$ & 2.14 \\
\hline & Constructive & 159 & $2.78(4.17)$ & $\begin{array}{l}\text { Unresolved } \\
\text { Constructive }\end{array}$ & $t(153)=15.87^{* *}$ & 1.75 \\
\hline \multirow[t]{3}{*}{ Cognitive representation } & Destructive & 158 & $2.78(4.17)$ & $\begin{array}{l}\text { Destructive } \\
\text { Unresolved }\end{array}$ & $t(157)=-4.36^{* *}$ & 0.34 \\
\hline & Unresolved & 160 & $2.47(3.56)$ & $\begin{array}{l}\text { Destructive } \\
\text { Constructive }\end{array}$ & $t(156)=-32.45 * *$ & 3.61 \\
\hline & Constructive & 159 & $\begin{array}{l}16.15 \\
(3.99)\end{array}$ & $\begin{array}{l}\text { Unresolved } \\
\text { Constructive }\end{array}$ & $t(157)=-30.60 * *$ & 3.14 \\
\hline \multirow[t]{3}{*}{ Behavioral regulation } & Destructive & 154 & $\begin{array}{l}10.51 \\
(6.81)\end{array}$ & $\begin{array}{l}\text { Destructive } \\
\text { Unresolved }\end{array}$ & $t(150)=-2.41^{*}$ & 0.21 \\
\hline & Unresolved & 155 & $\begin{array}{l}11.83 \\
(5.40)\end{array}$ & $\begin{array}{l}\text { Destructive } \\
\text { Constructive }\end{array}$ & $t(149)=-3.06^{* *}$ & 0.31 \\
\hline & Constructive & 156 & $\begin{array}{l}12.37 \\
(4.83)\end{array}$ & $\begin{array}{l}\text { Unresolved } \\
\text { Constructive }\end{array}$ & $t(151)=-0.98$ & 0.10 \\
\hline
\end{tabular}

$p<.05^{*}, p<.01^{* *}$

The results from t-tests showed that there were significant differences in the cognitive representation of degree of resolution of the three types of conflicts. Large effect sizes were observed reflecting that constructive conflict was viewed as more resolved than either destructive or unresolved conflicts. Unresolved conflict was significantly more resolved than destructive conflict with a small effect size as measured by Cohen's $d$ (Table 4).

In interpreting participants' endorsement of the various behavioral regulation strategies (Table 4), higher scores indicated greater participant interference in the conflict, with scores ranging from 0 to 20. Participants' interference was higher in constructive conflicts. There were significant differences in behavioral regulation in comparisons of (a) destructive and unresolved conflicts, respectively, and (b) destructive and constructive conflicts, respectively, although observed effect sizes were small.

Correlations (Table 3) showed significant relationships between the emotional reactivity, the cognitive representations, and the behavioral regulation of destructive and unresolved conflicts, which emphasize the similarities in responding to these types of conflicts. Behavioral responses to unresolved and constructive conflict were also significantly correlated. Emotional reactivity was significantly related to behavioral regulation for unresolved conflict while emotional reactivity was related to cognitive representations for constructive conflict. 
With regard to our second aim - to identify possible differences in adolescents' emotional security and reactivity to analog IPC depending on their living arrangement allocation (CF versus RC) we found no differences in emotional security between the groups. Power analyses for all pairwise comparison between-group (RC and CF participants) without taking into account types of conflict was 0.23 . These outcomes may well reflect that adolescents were recruited based on their levels of SIFS' emotional security, so that the numbers of high and low secure adolescents were balanced in both settings. Additionally, our sample was underpowered to detect small effects between groups, which may have contributed to the null findings. Nonetheless, despite the control for overall security, there were significant differences between $\mathrm{CF}$ and RC groups in both specific patterns of emotional insecurity assessed by the SIFS, that is, preoccupation and disengagement. $\mathrm{RC}$ adolescents were more preoccupied and disengaged in response to their family conflicts compared to CF adolescents, $t(155)=4.54, p<.001$, Cohen's $d=0.73$ and $t(157)=2.28, p=.02$, Cohen's $d=0.36$ respectively. These results reflect a medium effect size for this comparison for preoccupation and a small effect for this comparison for disengagement.

Analyses of emotional reactivity in $\mathrm{CF}$ and $\mathrm{RC}$ adolescents showed that there were significant differences in responses to constructive conflict. RC adolescents showed significantly heightened negative emotions than $\mathrm{CF}$ adolescents after watching constructive conflicts, $t(157)=-2.02$, $p=.04$, with a small effect size, Cohen's $d=0.32$. Notably, RC adolescents perceived constructive conflicts as significantly less resolved than did CF adolescents, $t(157)=2.06, p=.03$, with a small effect size, Cohen's $d=0.32$. Thus, our second hypothesis was partially supported as RC adolescents were more reactive than $\mathrm{CF}$ adolescents; however, only to constructive conflict and not to all forms of family conflict.

Regarding our third aim, we considered adolescents responses to IPC depending on their levels of emotional security. There were significant differences in the cognitive representation of conflict resolution for constructive conflict between adolescents with high and low emotional security, $t(157)=-2.71, p=.00$, with a small effect size, Cohen's $d=0.43$. Adolescents with low emotional security saw constructive conflicts as less resolved. Correlations between family insecurity defined by disengagement and preoccupation showed significant relations between preoccupation and behavior regulation for destructive conflict, $r(149)=-.25, p=.002$. The higher the preoccupation, the less adolescents interfered in destructive analog conflicts. Our third hypothesis was partially supported as adolescents low in emotional security were more reactive than adolescents high in emotional security to both constructive conflict and destructive conflict, both cognitively and behaviorally.

In order to address our fourth aim, we combined levels of emotional security and living arrangement allocation while controlling for other socio-demographic variables. Emotional, cognitive and behavioral responses to destructive, unresolved and constructive conflicts were subjected to a $2 \times 2 \times 3$ ANCOVA considering two levels of emotional security, two levels of living arrangement allocations, and three levels of conflict endings with covariates of gender and type of family (two parent, single parent and other family forms). The interaction effect was not significant in any analyses.

Gender was a significant factor for positive emotional reactivity to destructive conflict, reflecting that boys had more positive emotional reactivity to destructive conflict $M=0.97$ $(S D=3.2)$ compared to girls, $M=0.13(S D=1.17)$ (see Table 5). Gender differences were also found for negative emotional reactivity to destructive conflict, showing that boys had less negative emotional reactivity to destructive conflict $M=11.13(S D=4.64)$ compared to girls, $M=13.27$ $(S D=4.06)$. Significant differences were found for cognitive responses to destructive conflict, reflecting that RC adolescents saw destructive conflicts as more resolved, $M=2.85(S D=4.15)$ than $\mathrm{CF}$ adolescents, $M=1.91(S D=2.51)$. We calculated the mean differences between the degree of resolution of destructive and constructive conflicts as rated by $\mathrm{RC}$ and $\mathrm{CF}$ adolescents. The mean differences were significantly different from each other, $t(155)=-2.62, p=.00$, Cohen's $d=0.41$, indicating that the distinctions made for degree of resolution between destructive and 
constructive conflict was significantly smaller for adolescents in RC than it was for CF adolescents.

Table 5. ANCOVA results considering two levels of emotional security (low and high), two levels of living arrangement allocation (living with their families, CF, and in Residential care, RC) and three levels of conflict endings with covariates gender and type of family (two parent, single parent and other family forms)

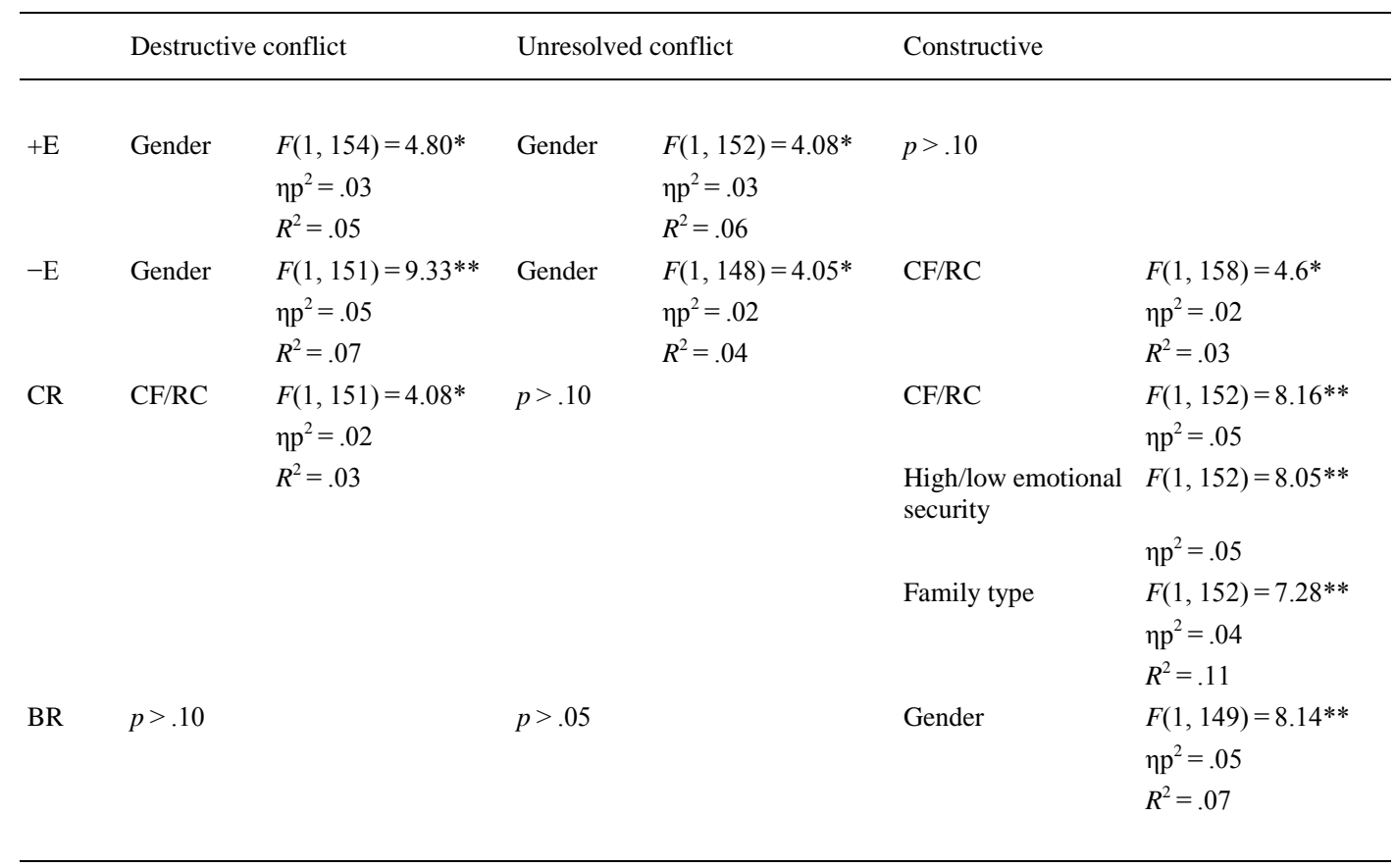

$E R+$ positive emotional reactivity, $E R-$ negative emotional reactivity, $C R$ cognitive representations, $B R$ behavioral regulation $* p<.05$ and $* * p<.01$

When considering unresolved conflicts, gender differences were found for both positive and negative emotional reactivity. Compared to girls, boys had more positive, $M=1.6(S D=3.66)$, $M=0.53(S D=2.14)$, and less negative, $M=10.15(S D=5.01), M=11.79(S \mathrm{D}=4.89)$, emotional reactivity.

In analyzing constructive conflicts, we found significant differences between RC and $\mathrm{CF}$ adolescents in terms of negative emotional reactivity. Adolescents in RC had more intense negative emotional reactivity $M=3.34(S D=4.63)$ to constructive conflicts than $\mathrm{CF}$ adolescents, $M=2.05(S D=3.39)$. With regard to cognitive representations, RC adolescents perceived constructive conflicts as less resolved than CF adolescents, $M=15.59(S D=4.47)$ and $M=16.89$ $(S D=3.12)$, respectively. Adolescents in the high emotional security group perceived constructive conflicts more resolved, compared to adolescents in the low emotional security group, $M=17.05$ $(S D=3.01)$ and $M=15.36(S D=4.56)$. Adolescents from single parent families perceived constructive conflicts as less resolved, $M=15.11(S D=4.31)$ than adolescents from two parent families, $M=16.22(S D=4.09)$ or adolescents in other family forms, $M=17.58(S D=2.69)$. Finally, a gender difference was found for behavioral regulation; girls were more likely to indicate that they would get involved than boys in constructive conflicts, $M=13.5(S D=4.45)$ and $M=11.45(S D=4.96)$ respectively. 


\section{Discussion}

Consistent with past research, the findings showed that adolescents differentiated constructive conflicts from destructive (escalating) and unresolved conflicts (Cummings et al. 2002; Koss et al. 2011). In fact, the power of 1.0 in detecting within-group effects, or differences in how adolescents perceive the type of conflict, means that we were able to detect small effects even when controlling for levels of emotional security and living allocation.

Differences as a function of living arrangements, that is, $\mathrm{CF}$ compared to $\mathrm{RC}$ groups, manifested particularly in adolescents' reactivity to constructive conflict, despite controlling for overall levels of emotional security. Consistent with EST-R, the Social Defense System may activate differently as a function of living arrangements, specifically for CF and RC groups, which is evident in the way these adolescents responded emotionally and interpreted the constructiveness (degree of resolution) of constructive conflicts. RC adolescents, compared to their counterparts who lived at home with parents, evaluated constructive conflicts as less resolved, and were more negatively emotional when confronted with constructive conflicts, signifying sensitization to any conflicts, even constructive conflicts. As Thompson et al. (2008) pointed out, when children face prolonged difficult circumstances their efforts to cope become less optimal over time and may result in less healthy emotional or behavioral regulation outcomes. Thus, this phenomenon may be related to their life circumstances or experiences.

Emotion regulation is a developmental task, and several family factors, such as the interparental relationship or the family climate, have been identified as relevant to either favor or compromise it (Fosco and Grych 2012). Certainly, an unstable, conflictual family life may compromise adolescents' emotional reactivity and emotional regulation, and RC adolescents especially come from adverse family contexts (Luzón García and Domínguez Alonso 2014; Martín and Dávila 2008). RC adolescents' sensitization to IPC, mainly manifested through their emotions and cognitions towards constructive conflicts, is in accordance with the idea that emotion regulation is multifaceted in its constituents and manifestations (Thompson et al. 2008). The present findings break new ground in suggesting that living contexts of adversity (i.e., the RC group) may undermine responding even to constructive conflict, so that adolescents exposed to living contexts of adversity (i.e., the RC group) do not identify when conflicts are solved, show a lower range of cognitive representations of conflict resolution to different conflict forms, and evidence heightened negative emotionality despite a context of optimal conflict behaviors. Given the adaptive value of knowing how to identify, respond to, and engage in constructive conflict, this may reflect an especially maladaptive coping pattern.

Interestingly, $\mathrm{RC}$ adolescents also showed a blunted response to destructive conflicts, often rating destructive conflicts as less destructive than did their $\mathrm{CF}$ counterparts. The failure to respond appropriately to actually threatening contexts may also be maladaptive over time. We propose that this pattern of responding may reflect sensitization to chronic stress as observed in biofeedback mechanisms, specifically in patterns of cortisol responding to stress in samples of children exposed to various contexts of trauma and stress (Ouellet-Morin et al. 2011; Doom et al. 2014). Thus, in a context of chronic stress, these adolescents had a lower threshold for reactivity in response to conflicts, however constructive; at the same time, their level of reactivity quickly reached a plateau even when the destructiveness of the conflict increased. This pattern of sensitization in the face of optimal circumstances of conflict expression, and reduced response to real threats, may leave children especially vulnerable to chronic stress and anxiety, with little hope of relief from concerns about contexts of conflict even when conflicts proceed in constructive ways. 
Patterns of emotional insecurity in the RC group also raise concerns, even when levels of overall emotional security were controlled by balancing high and low emotional secure levels on the SIFS security subscale. That is, RC adolescents evidenced greater patterns of preoccupied and disengaged insecure responding compared to $\mathrm{CF}$ adolescents. This stresses the need to address emotional security and emotion regulation in RC adolescents. Emotional security has an adaptive role in children functioning (Cummings and Davies 2010), and, if family conditions do not change when RC adolescents return home, their heightened emotional insecurity may be maladaptive over time. That is, if behaviors that result as a consequence of emotional insecurity persist in response to threats, these behaviors are likely to be maladaptive for the long term (Davies et al. 2002).

Moreover, when differentiating between high and low emotional secure adolescents, differences are evident in adolescents' cognitive representations of constructive conflict. More secure adolescents interpret constructive conflicts more constructively. According to EST's predictions, emotionally insecure adolescents interpret constructive conflicts less positively (Davies et al. 2002). This could also explain that adolescents from single parent families interpret constructive conflicts less constructively (less resolved). However, perceived constructiveness also depends on emotional reactivity, so those adolescents who feel more positive emotions when watching IP analog conflicts also interpret conflicts more constructively.

Adolescents' behavioral responses were highly influenced by the conflict's characteristics (destructive, unresolved, or constructive) and their own emotional insecurity. The results were consistent with studies that state that children are less likely to get involved if parents' behaviors are threatening for them (Davies and Martin 2014; Davies and Sturge- Apple 2007; Harold et al. 2004; Rhoades 2008). From our results, it appears that type of conflict (destructive or unresolved) and emotional insecurity (more preoccupation) relate to the likelihood of less behavioral involvement. This may have an adaptive effect considering that previous studies have identified that psychological problems are more likely to happen when higher emotional reactivity combines with heightened involvement in IPC (Davies et al. 2015).

In spite of inconclusive results of previous studies about gender patterns of response to IPC (Cummings and Davies 2010), in this study, a pattern was identified for emotional reactivity, evidencing that boys are less negatively activated by destructive and unresolved conflicts compared to girls, while girls are more prone to interfere in constructive conflicts. However, while intriguing, given the novelty of these findings, general conclusions about gender differences along these lines require replication and should be the subject of future research.

Our research is unique in this area of study in the population that we studied. Our data stress that EST can be applied to interpret adolescents' responses to simulated IPC in RC adolescents and not only to adolescents cohabitating with their families. Our findings also demonstrate that EST can be used in countries that are culturally and linguistically different from the country where it was initially developed (i.e., Spain). Our results also have implications for understanding RC adolescents' greater risk for adjustment problems because of their heightened emotional insecurity and their emotional reactivity to simulated constructive IPC and their narrower range of cognitive responses to different conflict forms, which we can hypothesize also occur outside of the laboratory. 


\section{Limitations}

The limitations of this study include the sample size, which may explain that no significant interaction effect was detected in the $2 \times 2 \times 3$ ANCOVA. However, even with a sample smaller than the recommended $n=208$, some exploratory results were supported. The research design allowed us to differentiate effects of living arrangement and emotional security, but a tradeoff in making this research design choice is that the findings likely underestimate overall emotional insecurity in RC groups, although, this design has shown that there are adolescents in RC with high emotional security as measured by SIFS subscale. Nonetheless, even with these rigorous controls, significant differences emerged in patterns of insecurity in RC compared to CF adolescents. Future research may make necessary to identify levels of emotional security with a combined measure of SIFS dimensions not just one subscale.

In this article, we were specifically interested in examining adolescents' responses following an emotional security framework, but further information about adolescents' well-being or adjustments was not collected. Still, our results have implications for future research, which emphasize the importance of examining adolescents' responses to various types of conflicts not just destructive conflicts. For example, it would be interesting to employ a holistic approach to examining adolescents' responses, including physiological responses. Further studies investigating the effect of personality traits and emotional reactivity and emotional regulation skills in adolescents on cognitive representations of conflicts may shed light on possible mechanisms mediating adolescents' responses to IPC. Other future detailed analyses may let us identify if there are adolescents with stable patterns of regulatory responses regardless of the conflict type and relate these patterns with socio-emotional and security variables.

\section{Acknowledgements}

Thanks to Xunta de Galicia for facilitating information and access to the child protection centers and to the professionals who helped us (headmasters, teachers, actors, video professionals, etc). This research did not receive any specific grant from funding agencies in the public, commercial, or not-for-profit sectors.

\section{Authors Contributions}

S.L.-L.: co-designed the study, reviewed the database, analyzed the data and wrote the paper. V.S.-S. collected and entered data, and assisted with writing and reviewing. A.P.H. analyzed data and assisted with analyses, with reviewing and writing. E.M.C. co-designed the study, reviewed the manuscript, suggested analyses and assisted with reviewing and writing.

\section{Compliance with Ethical Standards}

\section{Conflict of Interest}

The authors declare that they have no conflict of interest.

\section{Ethical Approval}

IRB approval for the study was provided by the Department of Family, Children and Demographic revitalization (Dirección Xeral de Familia, Infancia e Dinamización Demográfica) of the local (Galician) Government. Parents or legal tutors of the participants or the institutions guarding them (for adolescents in child protections services centers) gave their informed consent for the adolescents to participate and all adolescents assented. 


\section{References}

Buehler, C., Lange, G., \& Franck, K. L. (2007). Adolescents' cognitive and emotional responses to marital hostility. Child Development, 78(3), 775-789.

Campos, G. (2013). Transición a la vida adulta de los jóvenes acogidos en residencias de protección (Doctoral dissertation). Madrid (Spain): Universidad Autónoma de Madrid.

Cohen, J. (1988). Statistical power analysis for the behavioral sciences. 2nd ed. Hilllsdale, NJ: Erlbaum.

Criado del Rio, M., Castellano- Arroyo, M., \& Sánchez Blanque, A. (1990). Características del medio familiar de los menores institucionalizados, delincuentes y no delincuentes. Psicopatología, 10, $7-10$.

Cummings, E. M. (1995). The usefulness of experiments for the study of the family. Journal of Family Psychology, 9, 175-185.

Cummings, E. M., Ballard, M., El-Sheikh, M., \& Lake, M. (1991). Resolution and children's responses to interadult anger. Developmental Psychology, 27(3), 462-470.

Cummings, E. M., \& Davies, P. (1994). Children and marital conflict: The impact of family dispute and resolution. New York, NY: Guilford Press.

Cummings, E. M., \& Davies, P. T. (1999). Depressed parents and family functioning: Interpersonal effects and children's functioning and development. In T. Joiner \& J. Coyne (eds.), The interactional nature of depression: Advances in interpersonal approaches (pp. 299-327). Washington, DC: American Psychological Association.

Cummings, E. M., \& Davies, P. T. (2002). Effects of marital conflict on children: recent advances and emerging themes in process-oriented research. Journal of Child Psychology and Psychiatry and Allied Disciplines, 43, 31-63.

Cummings, E. M., \& Davies, P. T. (2010). Marital conflict and children. New York, NY: Guildford Press.

Cummings, E. M., Goeke- Morey, M., \& Papp, L. M. (2003). Children`s responses to everyday marital conflict tactics in the home. Child Development, 74(6), 1918-1929.

Cummings, E. M., Goeke-Morey, M., Papp, L. M., \& Dukewich, T. L. (2002). Children's responses to mothers'and fathers'emotionality and tactics in marital conflict in the home. Journal of Family Psychology, 16(4), 478-492.

Cummings, E. M., Koss, K. J., \& Davies, P. T. (2015). Prospective relations between family conflict and adolescent maladjustment: security in the family system as a mediating process. Journal of Abnormal Child Psychology, 43, 503-515.

Cummings, E. M., \& Miller-Graff, L. E. (2015). Emotional security theory: an emerging theoretical model for youths' psychological and physiological responses across multiple developmental contexts. Current Directions in Psychological Science, 24(3), 208-213.

Cummings, E. M., Vogel, D., Cummings, J. S., \& El- Sheikh, M. (1989). Children's responses to different forms of expression of anger between adults. Child Development, 60, 1392-1404.

Davies, P. T., Coe, J. L., Martin, M. J., Sturge-Apple, M. L., \& Cummings, E. M. (2015). The developmental costs and benefits of children's involvement in interparental conflict. Developmental Psychology, 51(8), 1026-1047.

Davies, P. T., Forman, E. M., Rasi, J. A., \& Stevens, K. I. (2002). Assessing children's emotional security in the interparental subsystem: the Security in the Interparental Subsystem (SIS) scales. Child Development, 73, 544-562.

Davies, P. T., Harold, G. T., Goeke-Morey, M., \& Cummings, E. M. (2002). Children's emotional security and interparental conflict. Monographs of the Society for Research in Child Development, 67, 1-129.

Davies, P. T., Hentges, R. F., Coe, J. L., Martin, M. J., Sturge-Apple, M. L., \& Cummings, E. M. (2016). The multiple faces of interparental conflict: implications for cascades of children's insecurity and externalizing problems. Journal of Abnormal Psychology, 125(5), 664-78.

Davies, P. T., \& Martin, M. (2014). Children's coping and adjustment in high-conflict homes: the reformulation of emotional security theory. Child Development Perspectives, 24(8), 242-249.

Davies, P. T., Myers, R. L., \& Cummings, E. M. (1996). Responses of children and adolescents to marital conflict scenarios as a function of the emotionality of conflict endings. Merrill-Palmer Quarterly, 42(1), 1-21.

Davies, P. T., Myers, R. L., Cummings, E. M., \& Heindel, S. (1999). Adult conflict history and children's subsequent responses to conflict: an experimental test. Journal of Family Psychology, 13(4), 610-638. 
Davies, P. T., \& Sturge- Apple, M. L. (2007). Advances in the formulation of emotional security theory: an ethologically based perspective. Advances in Child Behavior and Development, 35, 87-137.

Doom, J. R., Cicchetti, D., \& Rogosch, F. A. (2014). Longitudinal patterns of cortisol regulation differ in maltreated and nonmaltreated children. Journal of the American Academy of Child and Adolescent Psychiatry, 53(11), 1206-1215.

El-Sheikh, M., Ballard, M., \& Cummings, E. M. (1994). Individual differences in preschoolers' physiological and verbal responses to videotaped angry interactions. Journal of Abnormal Child Psychology, 22, 303-320.

Forman, E., \& Davies, P. T. (2005). Assessing children's appraisals of security in the family system: the development of the Security in the Family System (SIFS) scales. Journal of Child Psychology and Psychiatry, 46(8), 900-916.

Fosco, G. M., \& Grych, J. H. (2012). Capturing the family context of emotion regulation: a family systems model comparison approach. Journal of Family Issues, 34(4), 557-578.

Goeke- Morey, M. C., Cummings, E. M., \& Papp, L. M. (2007). Children and marital conflict resolution: implications for emotional security and adjustment. Journal of Family Psychology, 21(4), 744-753.

Goeke-Morey, M. C., Cummings, E. M., Harold, G., \& Shelton, K. H. (2003). Categories and continua of destructive and constructive marital conflict tactics from the perspective of U.S and Welsh Children. Journal of Family Psychology, 17(3), 327-338.

Goeke-Morey, M., Papp, L. M., \& Cummings, E. M. (2013). Changes in marital conflict and youths' responses across childhood and adolescence: a test of sensitization. Development and psychopathology, 25, 241-251.

Grych, J. H., \& Fincham, F. D. (1993). Children's appraisals of marital conflict: initial investigations of the cognitive-contextual framework. Child Development, 64, 215-230.

Ha, A. P., Bergman, K. N., Davies, P. T., \& Cummings, E. M. (2018). Parental postconflict explanations: implications for children's adjustment outcomes. Family Court Review, 56(2), 219-233.

Harold, G. T., Shelton, K. H., Goeke-Morey, M. C., \& Cummings, E. M. (2004). Marital conflict and child adjustment: Prospective longitudinal tests of the mediating role of children's emotional security about family relationships. Social Development, 13(3), 350-376.

Kreidler, S. M., Muller, K. E., Grunwald, G. K., Ringham, B. M., Coker-Dukowitz, Z. T., Sakhadeo, U. R., Barón, A. E., \& Glueck, D. H. (2013). GLIMMPSE: online power computation for linear models with and without a baseline covariate. Journal of Statistical Software, 54(10), 1-26. http://www.ncbi.nlm.nih.gov/pmc/articles/PMC3882200/.

Koss, K. J., George, M. R. W., Bergman, K. N., Cummings, E. M., Davies, P. T., \& Cicchetti, D. (2011). Understanding children's emotional processes and behavioral strategies in the context of marital conflict. Journal of Experimental Child Psychology, 109, 336-352.

López Larrosa, S., Sánchez Souto, V., \& Mendiri-Ruiz de Alda, P. (2012). Los adolescentes y el conflicto interparental destructivo: impacto en la percepción del sistema familiar y diferencias según el tipo de familia, la edad y el sexo de los adolescentes. Universitas Psychologica, 11(4), 1262-1274.

López-Larrosa, S., Mendiri-Ruiz de Alda, P., \& Sánchez Souto, V. (2016). Validación de la escala Seguridad en el Sistema Familiar (SIFS) en dos muestras españolas de adolescentes y jóvenes residentes con su familia e institucionalizados. Universitas Psychologica, 15(2), 361-370.

Luzón García, A., \& Domínguez Alonso, J. (2014). El menor infractor que comete su primer delito. Revista sobre la infancia y la adolescencia, 7, 40-57.

Martín, E., \& Dávila, L. M. (2008). Redes de apoyo social y adaptación de los menores en acogimiento residencial. Psicothema, 20(2), 229-235.

McCoy, K., Cummings, E. M., \& Davies, P. T. (2009). Constructive and destructive marital conflict, emotional security and children's prosocial behavior. Journal of Child Psychology and Psychiatry, 50(3), 270-279.

Muñiz, J., Elosúa, P., \& Hableton, R. K. (2013). Directrices para la traducción y adaptación de los tests: segunda edición. Psicothema, 25(2), 151-157.

Ouellet-Morin, I., Odgers, C. L., Danese, A., Bowes, L., Shakoor, S., Papadopoulos, A. S., Caspi, A., Moffitt, T. E., \& Arseneault, L. (2011). Blunted cortisol responses to stress signal social and behavioral problems among maltreated/bullied 12-year-old children. Biological Psychiatry, 70(11), 1016-1023.

Richmond, M. K., \& Stocker, C. M. (2007). Changes in children's appraisals of marital discord from childhood through adolescence. Journal of Family Psychology, 21(3), 416-425.

Rhoades, K. A. (2008). Children's responses to interparental conflict: a meta-analysis of their association with child adjustment. Child Development, 79(6), 1942-1956. 
Sánchez-Souto, V., \& López-Larrosa, S. (2010). El conflicto en 8 historias. A Coruña: Servizo de Recursos Audiovisuales da Universidade da Coruña, A Coruña, Spain.

Schermerhorn, A. C., Cummings, E. M., DeCarlo, C. A., \& Davies, P. T. (2007). Children's Influence in the Marital Relationship. Journal of Family Psychology, 21(2), 259-26.

Shamir, H., Cummings, E. M., Davies, P. T., \& Goeke- Morey, M. C. (2005). Children's reactions to Marital Conflict in Israel and in the United States. Parenting: Science and Practice, 5(4), 371386.

Shelton, K. H., Harold, G. T., Goeke-Morey, M. C., \& Cummings, E. M. (2006). Children's coping with marital conflict: the role of conflict expression and gender. Social Development, 15(2), 232-247.

Shifflett- Simpson, K., \& Cummings, E. M. (1996). Mixed message resolution and children's responses to interadult conflict. Child Development, 67(2), 437-448.

Thompson, R. A., Lewis, M. D., \& Calkins, S. D. (2008). Reassessing emotion regulation. Child Development Perspectives, 2(3), 124-131. 